\title{
Adolescent Aggression: The Role of Peer Group Status Motives, Peer Aggression, and Group Characteristics
}

\author{
Robert Faris ${ }^{\star}$ and \\ University of California at Davis \\ Susan Ennett \\ University of North Carolina at Chapel Hill
}

\begin{abstract}
Recent studies of youth aggression have emphasized the role of network-based peer influence processes. Other scholars have suggested that aggression is often motivated by status concerns. We integrate these two veins of research by considering the effects of peer status motivations on subsequent adolescent aggression, net of their own status motivations, prior aggression, and peer behavior. We also explore different levels at which peer effects may occur, considering the effects of reciprocated and unreciprocated friendships as well as larger, meso-level peer groups. We anticipate that peer group effects are magnified by both size and boundedness as measured by Freeman's (1972) Segregation Index. We find that, net of the adolescent's aggression at time 1, both the aggressive behaviors and the status valuations of friends independently increase the likelihood of aggression at time 2, six months later. The aggressive behavior of friends who do not reciprocate the adolescent's friendship nomination has particular impact. The average status valuation of peer groups increases their members' likelihood of aggression, even after controlling for their own attitudes about status, their friends' attitudes, and their friends' aggressive behavior. This effect is magnified in large groups and groups with high Freeman segregation scores.
\end{abstract}

\section{Keywords}

Bullying; aggression; peer influence; reciprocity; peer group; network position; status motivation

\section{Introduction}

The high correlation between the behaviors of people and their friends is among the most robust findings in social science. Researchers have used social network methods to parse peer influence from selection effects, and most seem to agree that, for most behaviors, there exists at least some degree of influence (Ennett and Bauman, 1994; Wills and Cleary, 1999;

\footnotetext{
(C) 2010 Elsevier B.V. All rights reserved.

*Direct all correspondence to Robert Faris, rwfaris@ucdavis.edu, Department of Sociology, University of California at Davis, 2247 Social Sciences and Humanities, One Shields Avenue, Davis, CA 95616 (telephone: 510-221-8876).

Publisher's Disclaimer: This is a PDF file of an unedited manuscript that has been accepted for publication. As a service to our customers we are providing this early version of the manuscript. The manuscript will undergo copyediting, typesetting, and review of the resulting proof before it is published in its final citable form. Please note that during the production process errors may be discovered which could affect the content, and all legal disclaimers that apply to the journal pertain.
} 
Christakis and Fowler, 2007; Steglich et al., 2007; Mercken et al., in press). This consensus is supported not only by longitudinal social network studies but experimental and quasiexperimental research as well (Zimmerman, 2003; Falk and Ichino, 2006; Campbell et al., 2008; Cook et al., 2008), and includes a wide range of prosocial (e.g., Hanushek et al., 2003) and risk (e.g., Haynie, 2001) behaviors.

While the bulk of the literature on aggression focuses on psychological problems and difficulties in the home (Roland, 2002; Rigby and Cox, 1996; O'Moore and Hillery, 1991; Austin and Joseph, 1996; O'Moore and Kirkham, 2001; Watson et al., 2004; Smith and Myron-Watson, 1998; Schwartz et al., 1997), increased use of social network methods has helped establish the role of peer influence. Mouttapa et al. (2004) found that sixth graders who had aggressive friends were significantly more likely to be aggressive, although the cross-sectional design precluded separating influence from selection effects. Espelage et al. (2003) found high levels of within-group similarity on different subtypes of aggression with peer group aggression predicting individual aggression even after controlling for individual baseline levels. Other studies have reinforced the role of peers in a very direct sense, finding that bullying and related forms of aggression are often perpetrated simultaneously by multiple adolescents (Craig and Pepler, 1997; Salmivalli et al., 1996), and that friends frequently target the same victims (Card and Hodges, 2006).

A second development in research on aggression, also associated with the social network approach, is the recent shift toward viewing aggression as instrumental for status attainment rather than a manifestation of poor mental health. Aggressive youth have been found to be no less socially competent or more depressed than bystanders (Olweus, 1993), and other researchers have suggested that aggression may also be strategic, purposeful behavior employed by "normal" adolescents to gain status (Pelligrini and Long, 2002; Veenstra et al., 2007; Hawley et al., 2007; Rodkin and Berger, 2008; Kreager, 2007). A recent study found that bullies were strongly motivated by status, and further, that bullying increased prestige (Sijtsema et al., 2009).

In this paper, we integrate both strains of research on aggression, examining the interplay of status motivations and the influences of immediate friends as well larger friendship groups. Specifically, we address four questions: 1) Are peer influence effects restricted to behavioral modeling, or do peers' attitudes about status also affect aggression? 2) Do some friends have more influence than others, specifically, unreciprocated versus reciprocated friends? 3) Is influence restricted to immediate friends, or can it be observed in larger friendship groups? 4) Do the properties of those friendship groups magnify their influence, specifically, group size and permeability as measured by the Freeman (1972) segregation index? In addressing all these questions, we control for prior aggression to adjust for selection processes. In the following sections, we provide the background for these research questions and present our hypotheses.

\section{Literature Review}

Bullying and related forms of aggression-we prefer the term aggression, as the term "bully" may connote physical or other overt forms of aggression to the exclusion of more subtle forms-is a serious social problem, affecting millions of American adolescents 
annually (Nansel et al., 2001). Victims are significantly more likely than others to experience suicidal ideation (Rigby and Slee, 1999, Kaltiala-Heino et al., 1999), social isolation (Nansel et al., 2001; Hay et al., 2003; Hodges and Perry, 1999), mental health problems (Olweus, 1993; Callagan and Joseph, 1995; O’Moore and Kirkham, 2001), physical health problems (Ghandour et al., 2003), and diminished academic performance (Eisenberg et al., 2003). The harm associated with aggression is not limited to victims; research suggests that aggressive youth often experience similar negative consequences to those of their victims (Olweus, 1993; Nansel et al., 2004; Swearer et al., 2001). Because much of the research on aggression is cross-sectional, however, many of the same psychological troubles that are considered to be outcomes of aggressive behavior by some researchers are considered to be causes by others. The result has been an overemphasis on maladjustment, to the detriment of other explanations.

We join others (e.g., Rodkin and Berger, 2008; Pelligrini and Long, 2002) in arguing that aggression can be instrumental for social goals, particularly that of social status. While theories of status hierarchies often implicitly assume that status is desired strongly and uniformly among actors (e.g., Gould, 2002), there is considerable variation in status motivation and actors who desire it more strongly are also more aggressive (Sijtsema et al., 2009). Formally, we test the following hypothesis:

\section{H1: Individual status motivation at time 1 increases the likelihood of aggression at time 2, net of aggression at time 1 .}

However, our primary concern is not the effect individuals' attitudes have on their own behavior, but the effect their peers' attitudes have on their behavior, net of their own attitudes. We argue that adolescents with status-oriented friends are likely to be aggressive even if they cares little about their own status. This can occur through pluralistic ignorance (Katz and Allport, 1931), whereby individuals overestimate, and subsequently conform to, attitudes and behavioral norms of groups to which they belong. Absent such misperceptions of peer values, the desire to remain in good standing may lead adolescents to engage in behaviors they would not otherwise. We also anticipate that peer attitudes may influence behavior net of peer behavior. That is, aggression is more likely to emerge among youth with status-oriented peers, even if they have not yet been aggressive. Thus, we build on the research finding evidence for direct behavioral influences on aggression (Mouttapa et al., 2004; Espelage et al., 2003) and test the following hypotheses.

$\mathrm{H} 2$. The average aggression level of an adolescent's friends at time 1 will be positively associated with the adolescent's aggression at time 2, net of the adolescent's aggression at time 1 .

H3. The average value an adolescent's friends place on status at time 1 will be positively associated with the adolescent's aggression at time 2, net of the adolescent's aggression at time 1 .

\section{Reciprocity}

Researchers who study adolescents' friendship networks typically restrict friendship nominations to a small number of "close" friends. However, not all "close friends" are 
equally close, and asymmetries exist even within networks defined by close friendships. In the widely-used Add Health study, students nominated their five closest male friends and their five closest female friends, yet even for the very "best" friends of the same gender, best-friend reciprocity is less than 50 percent (Strauss and Pollack, 2003) and the average adolescent has an overall reciprocity rate of only 37 percent (Ueno, 2005). Other studies have found that between one-fifth and one-third of adolescents have no reciprocated friendship nominations and that the majority of friendship nominations are unreciprocated (Parker and Asher, 1993; Vitaro et al., 2000; Cascairo et al., 1999).

Reciprocal friendships are characterized by greater emotional closeness (Newcomb and Bagwell, 1995), which may imply both greater capacity and opportunity for influence. Indeed, a longitudinal study of obesity found that mutual friends had the strongest influence on the target individual, while people whom the target nominated as a friend had weaker, but still significant influence; people who nominated the target as a friend but did not receive a nomination in return, had no significant effect (Christakis and Fowler, 2007). A longitudinal network analysis of adolescent smoking also found that mutual friendships had greater influence than unreciprocated ones (Mercken et al., in press). The reasons mutual friends have more influence on behaviors like substance use, obesity, and sexual activity often cannot be explained, however, by greater emotional closeness, interaction frequency, relationship duration, or geographic proximity (Bauman et al., 2007; Christakis and Fowler, 2007; Jaccard et al., 2005), leaving open the question of the mechanisms involved.

Unreciprocated friendships indicate, at the very least, an imbalance in the demand for the relationship, which might grant the receiver greater influence over the sender than the sender has over the receiver. Sociologists have treated unreciprocated relationship claims as prima facie evidence of lower status (Gould, 2002; Bearman, 1993) and other studies found they are associated with obesity, lower academic performance, reduced self-esteem, low status, and lower physical attractiveness (Strauss and Pollack, 2003; Cauce, 1986; Clark and Ayers, 1988). This suggests that, if aggression is status-oriented behavior, then we might expect friends who do not reciprocate the nomination to have more influence over an adolescent's behavior than those who do. To our knowledge, the only other study to examine the relationship found that aggression was most stable among aggressive children who had unreciprocated friendships with aggressive peers (Adams et al., 2005), suggesting greater influence on the part of these peers. We therefore test the following hypotheses:

H4: The aggressive behavior of unreciprocated friends at time 1 will increase an adolescent's aggression at time 2, net of the behaviors of mutual friends and the adolescent's aggression at time 1.

H5: The average status valuation of unreciprocated friends at time 1 will increase an adolescent's aggression at time 2, net of the attitudes of mutual friends and the adolescent's aggression at time 1.

\section{Social Position}

Social position is typically thought of in three general categories: members of dense friendship groups, bridges (or liaisons) who have friends in multiple groups but are not 
themselves group members, and those who are either hangers-on or isolated. Friendship groups are defined such that all group members send the majority of their friendship ties to other group members, and the group cannot be disconnected by the removal of any single friendship (Moody, 2001). Friendship groups are typically larger than an adolescent's immediate set of friends, though this may be due to nomination limits.

There are multiple approaches to finding groups within a network, but they seem to have similar results in small to medium-sized networks (Moody, 2001). Studies of adolescents have found that the majority of students are members of friendship groups, with fewer bridges, and still fewer isolates (Ennett and Bauman, 1994; Espelage et al., 2003). Social position may have direct effects on adolescent behavior (e.g., Ennett and Bauman, 1994), but adolescents are also more influenced by their friends' behavior when their friends are friends with each other, a defining characteristic of a friendship group (Haynie, 2001). A core proposition of network research on groups-but not one that is often tested-is that friendship groups are meaningful features of the network landscape, embodying meso-level sources of influence. We evaluate this proposition by testing the following hypotheses:

H6: The average aggression of an adolescent's friendship group at time 1 will increase aggression at time 2 , net of the aggression of close friends and the adolescent's aggression at time 1 .

$\mathrm{H} 7:$ The average status valuation of an adolescent's friendship group at time 1 will increase aggression at time 2 , net of the status valuation of close friends and the adolescent's aggression at time 1 .

We also anticipate that the effect of group-level factors may vary based on fundamental characteristics of groups. While some research has found that characteristics of networkderived groups influence their members regardless of the group's stability (Ryan, 2009) to our knowledge no study has considered whether size moderates the effect. Because larger friendship groups are more prominent in the school, we anticipate a positive interaction between group size and group attitudes and behaviors.

We also calculate the Freeman (1972) segregation index for each group, which measures the percent reduction in ties across group boundaries compared to a random graph. For example, a group with a segregation index of 0.80 would have $80 \%$ fewer ties to outsiders than we would expect based on a random graph. While the segregation indices for groups are high by definition, groups nonetheless vary in the permeability of their boundaries. We also anticipate that inward-oriented, impermeable groups will have stronger influences on their members, and thus test the following hypotheses:

H8: The effect of time 1 friendship group behaviors and status valuation on each member's aggression at time 2 will be stronger for those in larger groups, net of the member's aggression at time 1.

H9: The effect of time 1 friendship group behavior and status valuation on each member's aggression at time 2 will be stronger for those in groups with higher segregation scores, net of the member's aggression at time 1 . 


\section{Data and Methods}

Data for these analyses come from The Context of Adolescent Substance Use study (hereafter, Context), a longitudinal in-school survey of middle and high school students in three counties in North Carolina. Context focused on factors related to developmental trajectories of substance use and aggression across four contexts, the family, peer network, school, and neighborhood. The three participating counties are predominantly rural, with higher proportions of African-Americans and lower median incomes than national averages. Initially, all public school students in grades 6,7 , and 8 for each county were eligible, and eligibility was extended to new students at each wave. Ultimately, the total eligible study population was 8,201 , of which 7,173 (88\%), participated in at least one wave. The inschool survey began in the spring of 2002 with wave 1 and was administered every six months through wave 6 , which was collected in the fall of 2005 . After wave 6 , the study concluded with a final survey one year later, such that the oldest cohort was followed through $12^{\text {th }}$ grade. The response rate was maintained at or above $75 \%$ for each of the seven waves. Data for the current study are from wave 4 (hereafter, "time 1,") and 5 (hereafter, "time 2") because questions about aggression were added to the survey beginning at wave 4 . These timepoints correspond to the fall and spring of the 2004-5 school year, when students were in the $8^{\text {th }}, 9^{\text {th }}$, and $10^{\text {th }}$ grades. Both middle ( $8^{\text {th }}$ grade) and high schools $\left(9^{\text {th }}\right.$ and $10^{\text {th }}$ grades) were included. Using one school year avoids methodological problems associated with school and grade changes between school years. A total of 4,956 students completed at least some questions on the time 1 questionnaire, and after listwise deletion of missing data, a final sample of 4,516 students were included in the analysis. There were 16 schools in the analysis and 219 friendship groups.

\section{Measures}

To measure aggression and victimization, students were asked to nominate up to five schoolmates who "picked on or were mean to" them, and up to five peers whom they "picked on or were mean to." Respondents were instructed to disregard friendly or playful teasing, and other analyses (not shown) suggest victimization has serious negative consequences. The aggression and victimization networks (the network according to victims, and the network according to aggressors) were merged such that an aggressive tie from $A$ to $B$ was considered present if either $A$ nominated $B$ as a victim or $B$ nominated $A$ as an aggressor. This decision rule is based on both underreporting concerns and implications of the fixed number of nominations. With a restriction on the number of possible aggressors and victims a respondent can nominate (five each), the number 6 victim would not be nominated by the aggressor, but the aggressor might nonetheless be the primary aggressor for victim $6 .^{1}$

From the combined aggression networks, we calculated aggression outdegree, or the number of students toward whom the respondent was aggressive. Consistent with national

\footnotetext{
${ }^{1}$ There is significantly greater agreement $(71 \%)$ on the presence of an aggressive relationship than expected by chance. However, our results are nonetheless consistent with underreporting on the part of aggressors: if aggressor's reports are considered alone, only $15 \%$ of respondents would be classified as aggressive, compared to $25 \%$ based on victims' reports. Additionally, the distribution based on victim's reports is more skewed (up to a maximum of 9 , compared to the limit of 5 for aggressor's reports), implying that the limit on nominations may censor data on some aggressive relationships.
} 
prevalence estimates (Nansel et al., 2001), the majority (65\%) of students were not aggressive toward any of their classmates at time 2; among those who were aggressive, over half $(56 \%)$ targeted only one victim and the vast majority $(86 \%)$ targeted three or fewer (Table 1). To simplify the hierarchical analysis, we collapse the outdegree measure into a binary variable, which was coded as " 1 " if the adolescent was aggressive toward any peers during the time period under consideration and zero otherwise. Results are robust to the specification of the dependent variable, and there are no substantive changes in final models when the outdegree measure is used. All time-varying independent variables were observed at time 1 .

We are interested not in change in aggression per se, and of the two-thirds of adolescents whose aggression status did not change between time points, it is substantively important to distinguish between those who were continually aggressive and those who were never aggressive. ${ }^{2}$ Thus, rather than model change in the dependent variable, we instead include the binary indicator of aggression from time 1 in all models.

Our analysis focuses on two independent variables, peer aggression and peer status valuation. The former is the average aggression outdegree for a given set of peers (which varies through the analysis), while the latter was similarly created using a question asking respondents how important or unimportant "being popular" was to them. There were four response categories ranging from "very important" (coded 3) to "not at all important" (coded 0 ). The distribution of responses (not shown) is nearly uniform, with each of the four response categories receiving between 23 and $26 \%$ of the selections, and the mean for all students was 1.58 .

Friendship networks were created using a question asking respondents to name up to five of their closest friends, starting with their very best friend. Rather than limit friendship nominations to the classroom, as appropriate for middle and high school students, students were given rosters including all students in the school who were also in the eligible study grades. We start with the average aggression and status valuation of all friends, then create averages for different categories of friends: "in-friends," classmates who nominated the respondent as a friend, but who did not receive a nomination in return; "out-friends," classmates the respondent nominated as a friend, but who did not reciprocate the nomination; and mutual friends. On average, respondents have 2.0 in-friends, 2.9 outfriends, and 1.1 mutual friends. Some respondents do not have any friends in one or more categories. In those cases we code the value as zero, but include a control variable for the existence of each friend category to avoid distorting the results.

Network position was calculated using the "CROWDS" macro developed for SAS IML by James Moody (Moody, 2001) and similar to the algorithms used in NEGOPY (Richards, 1995). The program finds isolates, bridges, and friendship groups, in which the majority of members' links are to other group members. Friendship groups vary widely in size, ranging

\footnotetext{
${ }^{2}$ The correlation between time 1 and time 2 aggression outdegree is $0.38(\mathrm{p}<0.001)$, indicating substantial change between time points. However, most of this change is not due to binary changes in whether or not respondents were aggressive but to a net decrease in the number of victims per aggressor (overall average outdegree drops from 0.88 to 0.69 ; for those who were aggressive at time 1 , it drops from 2.1 to 1.07, and for those who were aggressive at both time points, it drops from 2.4 to 2.2 ).
} 
from 4 to 65 , though the majority of group members are in groups of less than 20 . We include the average aggression outdegree and average status valuation for the friendship group, but because some groups are quite small and thus their average scores are potentially sensitive to each individual member, we calculate these as average values of all group members excluding the respondent. However, results do not change substantively when the respondent is included. For isolates and bridge nodes, who by definition are not members of friendship groups, we substitute the averages for all other schoolmates in each category (i.e., for all other isolates and all other bridge nodes) for the friendship group variable, and we include control variables for bridges and isolates. Lastly, we also include the school averages for aggression outdegree and status valuation.

Control variables included in all models are gender (female as the reference), race/ethnicity (African-American, Latino, and other minority, with white as the reference), grade in school $\left(9^{\text {th }}, 10^{\text {th }}\right.$, with $8^{\text {th }}$ grade as the reference category), single parent home, and a variable indicating low parental educational attainment ( 1 if no parent attended college, 0 otherwise). In models with averages for specific categories of friends we control for whether the respondent has any friends in that category, and we also control for their position as a bridge or an isolate in models with group averages. Because we use a binary dependent variable and our data may be clustered at the group and school level, we estimate a multilevel logistic regression with random intercepts at the group and school levels.

\section{Results}

First, we estimate an unconditional random effects logistic model of aggression (not shown). The estimate of random variance at the school level was 0.08 (standard error: 0.04; 95\% CI: $0.03-0.23$ ) and the variance at the friendship group level was estimated to be 0.12 (standard error: 0.04 ; $95 \%$ CI: $0.06-0.25$ ). Finding significant variation at both levels, we maintain this model specification in conditional models (Table 2). Model 1 tests our first two hypotheses, and finds that both the aggressive behavior and the status valuation of friends increase an adolescent's likelihood of aggression six months later. One-unit increases in an adolescent's friends' aggression and status valuation increase his/her likelihood of being aggressive by $20 \%$ and $10 \%$, respectively. In models 2 through 4 , we consider the influence of friends separately by reciprocity. Classmates who nominate the adolescent as a friend, but do not receive a nomination in return ("in-friends"), appear to have no significant influence on the subsequent behavior of the focal adolescent (model 2). However, classmates who do not reciprocate the focal adolescent's nomination ("out-friends") do appear to influence the adolescent: a one-unit increase in the aggressive behavior of out-friends increases the focal adolescent's likelihood of aggression by $26 \%$ (model 3). We find significant but smaller effects for mutual friends (model 4), but the combined model (model 5) finds that only the status valuation of mutual friends influences the focal adolescent's likelihood of aggression, while the effect of unreciprocated friends' aggression remains.

Next we test the effects of friendship group and school-level status valuation and aggression (model 6). While school-level status valuation and aggression do not affect subsequent adolescent aggression, mean group status valuation is positively related to subsequent aggression. A one-unit increase in the friendship group's average valuation of status 
increases the likelihood of aggression by one-third. We also find that group attitudes about status have an effect on adolescent aggression even when individual attitudes are controlled (model 7).

Finally, we test our hypotheses about fundamental friendship group characteristics—size and segregation - as moderators of the effect of group values on aggression (table 3). Bridges and isolates are dropped for this analysis because group properties are not meaningful for these adolescents. Also, for parsimony, categories of in-friends, out-friends, and mutual friendships are collapsed. In order to facilitate interpretation of coefficients, we center all variables that are implicated in the interaction terms.

We first re-estimate our baseline model (model 1), which is similar to the final model in table 2 except for the changes listed above. We continue to find a significant effect of friendship group status valuation (and individual status valuation also becomes statistically significant). We then introduce the main effects of group size and segregation (model 2). The former has no direct effect on aggression, but the more segregated a group is, the less likely its members are to be aggressive: a one point increase in Freeman's segregation measure is associated with a six percent decrease in the likelihood of aggression.

Finally, we add the group size*status valuation and group segregation*status valuation interaction terms (model 3). Because the average group aggression level has no significant effect on the likelihood of aggression, we do not test those interactions. We find significant effects for both interaction terms and the main effect of group size becomes statistically significant and negative. We plot the predicted probabilities for the means of each variable and variation of one standard deviation in both directions (Figure 1). For friendship groups of average size and segregation, increases in the mean status valuation of the group increase the likelihood of aggression on the part of its members. This effect is heightened as group size and/or segregation increases, but is actually reversed for small and medium-sized groups with low segregation values.

\section{Discussion}

The motivation for this paper was to examine the intersection of two disparate explanations for aggression, peer aggression and status motivation, and to explore the different levels and relationships in which they operate. We hypothesized that concerns over status motivate aggression, that peer attitudes about status, and not only peer aggression, would increase the likelihood of aggression, that influence is stronger in asymmetric relationships, and that friendship groups - and their size and segregation — affect behavior, net of the influences of close friends.

With two exceptions (hypotheses 5 and 6), these hypotheses, were confirmed. Adolescents who care more about popularity are more likely to become aggressive. The aggressive behavior of friends who do not reciprocate an adolescent's nomination-arguably indicative of status differences-has a significant independent effect on that adolescent's subsequent aggressive behavior. Aggression is more likely when an adolescent's friendship group emphasizes social status, regardless of the group's level of aggression or the individual's 
own attitudes about status. This effect is stronger in larger, less permeable groups. We must note that the generalizability of these findings is limited by the study's North Carolina sample. The fixed number of friendship nominations may also have implications for the findings, and we hope future research considers other contexts and study designs.

\section{Conclusion}

Theoretical models have often implicitly treated aggression as a reaction to some provocation or problem, be it psychological maladjustment (Farrington and Baldry, 2010), an insult (Gould, 2003), an earlier act of aggression (Papachristos, 2009), or some source of frustration (Berkowitz, 1989). While not explicitly reactive, the recent emphasis on peer influence processes within social networks (Mouttapa et al., 2004; Espelage et al., 2003; Kreager, 2007) suggests aggression is a behavior that may be absorbed via modeling, through contact with aggressive peers. Even "proactive" aggression has been linked to problematic background factors like aggressive role models in the home (e.g., Dodge et al., 1997). Each of these veins of research has received considerable empirical support, but they largely ignore the possibility that aggression is caused in part by the anticipation of its consequences.

We instead echo arguments that aggression may be both motivated by, and instrumental for, social climbing (Rodkin and Berger, 2008; Pelligrini and Long, 2002; Sijtsema et al., 2009). We extend this general argument by showing that adolescents need not share the status motivations of their peer group in order to have their behavior affected by them. To the extent that this argument is true, the expected outcome of aggression-higher social statusprovides sufficient explanation for it, even when the aggressors do not personally hold those goals. Thus, in addition to searching for more antecedents, researchers might profit from focusing on why and how some types aggression are socially rewarded. The insight that status motivations - of self and others - can strongly influence aggression may extend to other behaviors in which peers are implicated.

\section{Literature Cited}

Adams R, Bukowski WM, Bagwell C. Stability of aggression during early adolescence as moderated by reciprocated friendship status and friend's aggression. International Journal of Behavioral Development. 2005; 29(2):139-145.

Austin S, Joseph S. Assessment of Bully/Victim Problems in 8 to 11 Year Olds. British Journal of Educational Psychology. 1996; 66:447-456. [PubMed: 9008423]

Bauman K, Faris R, Ennett S, Hussong A, Foshee V. Adding Valued Data to Social Network Measures: Does it add to associations with adolescent substance use? Social Networks. 2007; 29(1): $1-10$.

Bearman, P. ASA Rose Monograph Series. New Brunswick, NJ: Rutgers University Press; 1993. Relations into Rhetorics.

Bearman P, Moody J. Suicide and Friendships Among American Adolescents. American Journal of Public Health. 2004; 94(1):89-95. [PubMed: 14713704]

Berkowitz L. Frustration-Aggression Hypothesis: Examination and Reformulation. Psychological Bulletin. 1989; 106(1):59-73. [PubMed: 2667009]

Blanton, H.; Burkley, M. Deviance Regulation Theory: Applications to Adolescent Social Influence. In: Prinstein, Mitchel; Dodge, Kenneth, editors. Understanding Peer Influence in Children and Adolescents. New York, NY: The Guilford Press; 2008. 
Callagan S, Joseph S. Self-Concept and Peer Victimization Among Schoolchildren. Personality and Individual Differences. 1995; 18:161-164.

Campbell R, Starkey F, Holliday J, Audrey S, Bloor M, Parry-Langdon N, Hughes R, Moore L. An informal school-based peer-led intervention for smoking prevention in adolescence (ASSIST): a cluster randomised trial. The Lancet. 2008; 371(9624):1595-1602.

Card N, Hodges EV. Shared targets for aggression by early adolescent friends. Developmental Psychology. 2006; 42:1327-1338. [PubMed: 17087564]

Cascairo T, Carley KM, Krackhardt D. Positive affectivity and accuracy in social network perception. Motivation and Emotion. 1999; 23:285-306.

Cauce AM. Social networks and social competence: Exploring the effects of early adolescent friendships. American Journal of Community Psychology. 1986; 14(6):1573-2770.

Christakis NA, Fowler JH. The spread of obesity in a large social network over 32 years. New England Journal of Medicine. 2007; 357(4):370-379. [PubMed: 17652652]

Clark ML, Ayers M. The Role of Reciprocity and Proximity in Junior High Friendships. Journal of Youth and Adolescents. 1988; 17(5):403-411.

Cook PJ, MacCoun R, Muschkin C, Vigdor J. The negative impacts of starting middle school in sixth grade. Journal of Policy Analysis and Management. 2008; 27(1):104-121.

Craig WM, Pepler DJ. Observations of bullying and victimization in the schoolyard. Canadian Journal of School Psychology. 1997; 13:41-60.

Dodge KA, Lochman JE, Harnish JD, Bates JE, Pettit GS. Reactive and proactive aggression in school children and psychiatrically impaired chronically assaultive youth. Journal of Abnormal Psychology. 1997; 106:37-51. [PubMed: 9103716]

Eisenberg ME, Neumark-Sztainer D, Perry C. Peer harassment, school connectedness, and academic achievement. Journal of School Health. 2003; 73:311-316. [PubMed: 14593947]

Ennett S, Bauman K. The contribution of influence and selection to adolescent peer group homogeneity: The case of adolescent cigarette smoking. Journal of Personality \& Social Psychology. 1994; 67(4):653-663. [PubMed: 7965611]

Ennett S, Bauman K, Koch G. Variability in cigarette smoking within and between adolescent friendship cliques. Addictive Behaviors. 1994; 19(3):295-305. [PubMed: 7942247]

Ennett S, Faris R, Hipp J, Foshee V, Bauman K, Hussong A, Cai L. Peer Smoking, Other Network Attributes, and Adolescent Smoking: A Social Network Analysis. Prevention Science. 2008; 9:8898. [PubMed: 18404380]

Espelage D, Holt M, Henkel R. Examination of Peer-Group Contextual Effects on Aggression During Early Adolescence. Child Development. 2003; 74(1):205-220. [PubMed: 12625446]

Falk A, Ichino A. Clean Evidence on Peer Effects. Journal of Labor Economics. 2006; 24(1):39-57.

Farrington D, Baldry A. Individual Risk Factors for School Bullying. Journal of Aggression, Conflict, and Peace Research. 2010; 2(1):4-16.

Frank K, Muller C, Schiller K, Riegle-Crumb C, Strassman-Meuler A, Crosnoe R, Pearson J. The Social Dynamics of Mathematics Coursetaking in High School. American Journal of Sociology. 2008; 113(6):1645-1696.

Freeman LC. Segregation in Social Networks. Sociological Methods and Research. 1972; 6:411-430.

Ghandour R, Overpeck M, Huang Z, Kogan M, Scheidt P. Headache, Stomachache, Backache and Morning Fatigue Among Adolescent Girls in the United States. Archives of Pediatric Adolescent Medicine. 2003; 158:797-803.

Gould R. The Origins of Status Hierarchies: A Formal Theory and Empirical Test. American Journal of Sociology. 2002; 107(5):1143-1178.

Gould, R. Collision of Wills. Chicago: University of Chicago Press; 2003.

Hanushek EA, Kain JF, Markman JM, Rivkin SG. Does peer ability affect student achievement? Journal of Applied Econometrics. 2003; 18(5):527-544.

Hawley P, Little T, Card N. The Allure of the Mean Friend: Relationship Quality and Processes of Aggressive Adolescents with Prosocial Skills. International Journal of Behavioral Development. 2007; 31:170-180. 
Hay D, Payne, Chadwick A. Peer Relations in Childhood. Journal of Child Psychology and Psychiatry. 2003; 45:84-108. [PubMed: 14959804]

Haynie D. Delinquent Peers Revisited: Does Network Structure Matter? American Journal of Sociology. 2001; 106(4):1013-1057.

Hodges E, Perry D. Personal and Interpersonal Antecedents and Consequences of Victimization by Peers. Journal of Personality and Social Psychology. 1999; 76:677-685. [PubMed: 10234851]

Jaccard J, Blanton H, Dodge T. Peer Influences on Risk Behavior: an Analysis of the Effects of a Close Friend. Developmental Psychology. 2005; 41(1):135-147. [PubMed: 15656744]

Kaltiala-Heino R, Rimpelä M, Marttunen M, Rimpelä A, Rantanen P. Bullying, depression, and suicidal ideation in Finnish adolescents: school survey. British Medical Journal. 1999; 319:348351. [PubMed: 10435954]

Katz, D.; Allport, F. Student Attitudes. Syracuse, N.Y.: Craftsman; 1931.

Kreager D. When it's Good to Be 'Bad': Violence and Adolescent Peer Acceptance. Criminology. 2007; 45(4):893-923.

Kreager D. Unnecessary roughness? School sports, peer networks, and male adolescent violence. American Sociological Review. 2007; 72:705-724.

Mercken L, Snijders TAB, Steglich C, Vartiainen E, de Vries H. Dynamics of adolescent friendship networks and smoking behavior. Social Networks. 2010; 32(1):72-81.

Miller J, Lynam D. Reactive and Proactive Aggression: Similarities and differences. Journal of Personality and Individual Differences. 2006; 41:1469-1480.

Moody J. Peer influence groups: Identifying dense clusters in large networks. Social Networks. 2001; 23:261-283.

Mouttapa M, Valente T, Gallaher P, Rohrbach LA, Unger J. Social network predictors of bullying and victimization. Adolescence. 2004; 39:315-335. [PubMed: 15563041]

Nansel T, Overpeck M, Haynie D, Ruan J, Scheidt P. Bullying Behaviors Among US Youth: Prevalence and Association with Psychosocial Adjustment. Journal of the American Medical Association. 2001; 285:2094-2100. [PubMed: 11311098]

Nansel T, Craig W, Overpeck M, Saluja G, Ruan J. Cross-national Consistency in the Relationship Between Bullying Behaviors and Psychosocial Adjustment. Archives of Pediatrics and Adolescent Medicine. 2004; 158(8):730-736. [PubMed: 15289243]

Newcomb AF, Bagwell CL. Children's friendship relations: A meta-analytic review. Psychological Bulletin. 1995; 117:306-347.

O’Moore M, Kirkham M. Self-Esteem and Its Relationship to Bullying Behaviour. Aggressive Behavior. 2001; 27:269-283.

O’Moore, A.; Hillery, B. What Do Teachers Need to Know?. In: Elliott, M., editor. Bullying: A Practical Guide to Coping for Schools. Harlow: Longman; 1991. p. 56-69.

Olweus, D. Bullying At School: What we Know and What We Can Do. Cambridge: Blackwell; 1993.

Papachristos A. Murder by Structure: Dominance Relations and the Social Structure of Gang Homicide. American Journal of Sociology. 2009; 115(1):74-128.

Parker JG, Asher SR. Friendship and friendship quality in middle childhood: Links with peer group acceptance and feelings of loneliness and social dissatisfaction. Developmental Psychology. 1993; 29:611-621.

Pelligrini A, Long J. A longitudinal study of bullying, dominance, and victimization during the transition from primary school through secondary school. British Journal of Developmental Psychology. 2002; 20:259-280.

Richards, W. NEGOPY, Version 4.30. Burnaby, BC, Canada: Simon Fraser University; 1995.

Rigby K, Cox I. The Contribution of Bullying At School and Low Self-Esteem to Acts of Delinquency Among Australian Teenagers. Personality and Individual Differences. 1996; 21:609-612.

Rigby K, Slee P. Suicidal Ideation among Adolescent School Children, Involvment in Bully-Victim Problems, and Perceived Social Support. Suicide and Life-Threatening Behavior. 1999; 29:199_ 230. [PubMed: 10407971]

Rodkin P, Berger C. Who Bullies Whom? Social Status Asymmetries by Victim Gender. International Journal of Behavioral Development. 2008; 32(6):473-485. 
Roland E. Aggression, Depression, and Bullying Others. Aggressive Behavior. 2002; 28:198-206.

Ryan A. The Peer Group as a Context for the Development of Young Adolescent Motivation and Achievement. Child Development. 2009; 72(4):1135-1150. [PubMed: 11480938]

Salmivalli C, Lagerspetz K, Bjorkqvist K, Osterman K, Kaukiainen A. Bullying as a group process: Participant roles and their relations to social status within the group. Aggressive Behavior. 1996; 22:1-15.

Schwartz D, Dodge K, Pettit G, Bates J. The Early Socialization of Aggressive Victims of Bullying. Child Development. 1997; 68:665-675. [PubMed: 9306645]

Sijtsema J, Veenstra R, Lindenberg S, Salmivalli C. Empirical Test of Bullies' Status Goals: Assessing Direct Goals, Aggression, and Prestige. Aggressive Behavior. 2009; 35:57-67. [PubMed: 18925635]

Smith P, Myron-Wilson R. Parenting and School Bullying. Clinical Child Psychology and Pyschiatry. 1998; 3:405-417.

Steglich, C.; Snijders, T.; Pearson, M. Dynamic Networks and Behavior: Separating Influence from Selection. Working paper. 2007. available on the web at http://stat.gamma.rug.nl/snijders/ SteglichSnijdersPearson2007.pdf

Strauss R, Pollack H. Social Marginalization of Overweight Children. Archives of Pediatric and Adolescent Medicine. 2003; 157:746-752.

Swearer S, Song S, Cary P, Eagle J, Mickelson W. Psychosocial Correlates in Bullying and Victimization: The Relationship Between Depression, Anxiety, and Bully/Victim Status. Journal of Emotional Abuse. 2001; 2:95-121.

Ueno K. The effects of friendship networks on adolescent depressive symptoms. Social Science Research. 2005; 34:484-510.

Veenstra R, Lindenberg S, Zijlstra B, De Winter A, Verhulst F, Ormel J. The Dyadic Nature of Bullying and Victimization: Testing a Dual Perspective Theory. Child Development. 2007; 78:1843-1854. [PubMed: 17988325]

Vitaro F, Brendgen M, Tremblay RE. Influence of deviant friends on delinquency: Searching for moderator variables. Journal of Abnormal Child Psychology. 2000; 28:313-325. [PubMed: 10949957]

Watson M, Fischer K, Andreas B, Smith K. Pathways to Aggression in Children and Adolescents. Harvard Education Review. 2004; 74:404-430.

Wills TA, Cleary SD. Peer and Adolescent Substance Use Among $6^{\text {th }}-9^{\text {th }}$ Graders: Latent Growth Analyses of Influence Versus Selection Mechanisms. Health Psychology. 1999; 18(5):453-463. [PubMed: 10519461]

Zimmerman D. Peer Effects in Academic Outcomes: Evidence from a Natural Experiment. The Review of Economics and Statistics. 2003; 85(1):9-23. 




Group Average Status Valuation

Figure 1.

Predicted Probability of Aggresion, by Group Status Valuation, Group Size, and Group Segregation 


\section{Table 1}

\section{Descriptive Statistics}

\begin{tabular}{|c|c|c|c|c|}
\hline & Mean & S.D. & Min & Max \\
\hline Aggression at time 2 & 0.34 & 0.47 & 0 & 1 \\
\hline Aggression at time 1 & 0.39 & 0.49 & 0 & 1 \\
\hline Aggression outdegree & 0.88 & 1.41 & 0 & 9 \\
\hline Status valuation & 1.58 & 1.08 & 0 & 3 \\
\hline Friends' average aggression outdegree & 0.85 & 0.68 & 0 & 5 \\
\hline Friends' average status valuation & 1.59 & 0.63 & 0 & 3 \\
\hline \multicolumn{5}{|l|}{ Group and School Variables } \\
\hline Average aggression of group & 0.75 & 0.45 & 0.00 & 3.75 \\
\hline Average status valuation of group & 1.14 & 0.42 & 0.00 & 2.75 \\
\hline Average aggression of school & 0.69 & 0.25 & 0.00 & 1.30 \\
\hline Average status valuation of school & 1.02 & 0.13 & 0.55 & 1.28 \\
\hline Freeman segregation index (group members only) & 96.41 & 2.40 & 84.60 & 99.75 \\
\hline Group size (group members only) & 25.44 & 15.25 & 4.00 & 65.00 \\
\hline \multicolumn{5}{|l|}{ Control Variables } \\
\hline Male & 0.47 & 0.50 & 0 & 1 \\
\hline African-American & 0.32 & 0.46 & 0 & 1 \\
\hline Latino(a) & 0.04 & 0.20 & 0 & 1 \\
\hline Other minority & 0.07 & 0.24 & 0 & 1 \\
\hline White & 0.56 & 0.50 & 0 & 1 \\
\hline One parent & 0.33 & 0.47 & 0 & 1 \\
\hline No parent attended college & 0.34 & 0.47 & 0 & 1 \\
\hline $8^{\text {th }}$ grade & 0.35 & 0.48 & 0 & 1 \\
\hline $9^{\text {th }}$ grade & 0.33 & 0.47 & 0 & 1 \\
\hline $10^{\text {th }}$ grade & 0.31 & 0.46 & 0 & 1 \\
\hline Has in-friends & 0.72 & 0.45 & 0 & 1 \\
\hline Has out-friends & 0.74 & 0.44 & 0 & 1 \\
\hline Has mutual friends & 0.34 & 0.47 & 0 & 1 \\
\hline Group member & 0.60 & 0.25 & 0 & 1 \\
\hline Bridge node & 0.33 & 0.44 & 0 & 1 \\
\hline Isolate/hanger-on & 0.07 & 0.25 & 0 & 1 \\
\hline
\end{tabular}

$\mathrm{N}=4,516(2,664$ group members $)$ 


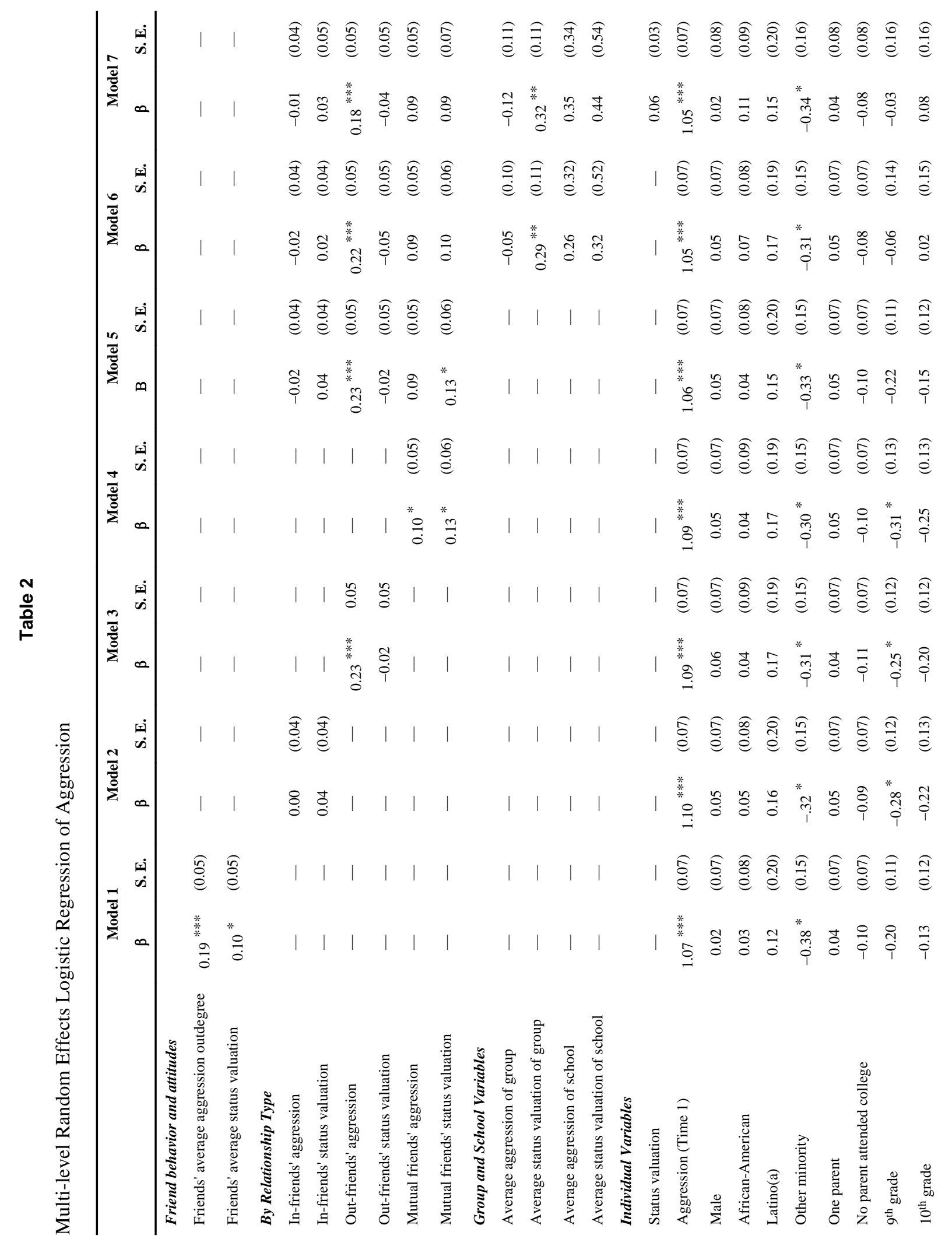









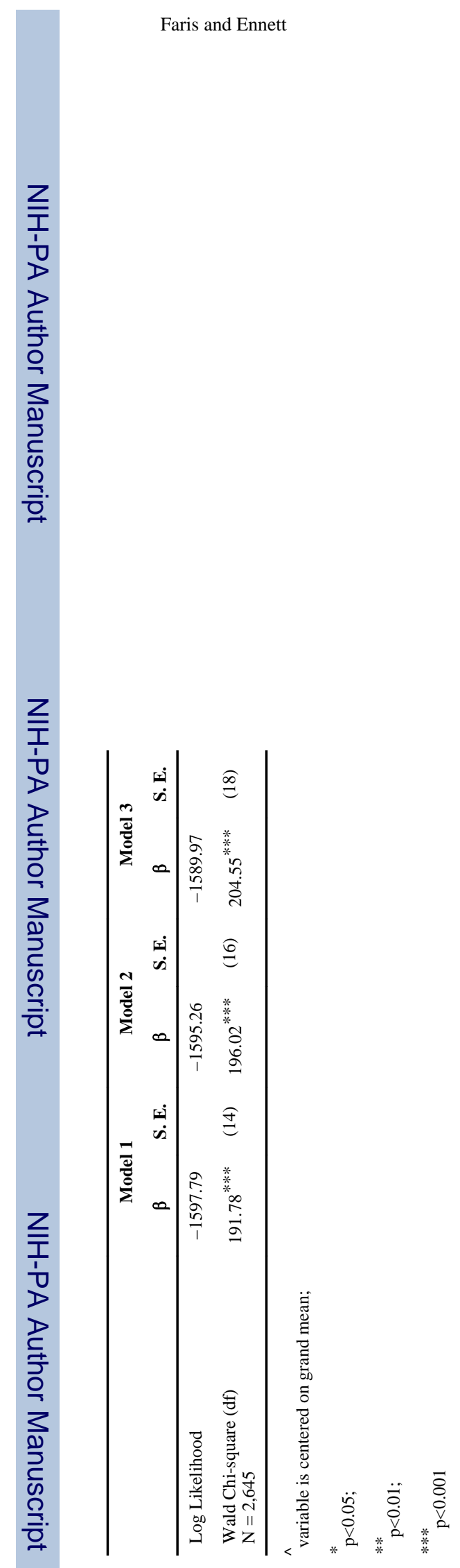

Soc Networks. Author manuscript; available in PMC 2014 August 20. 